Jurnal Konstruksi Hukum | ISSN: 2746-5055

Vol. 2, No. 2, Mei 2021, Hal. 250-254| Tersedia online di

https://www.ejournal.warmadewa.ac.id/index.php/jukonhum

DOI: https://doi.org/10.22225/jkh.2.2.3215.250-254

\title{
PERJANJIAN KERJASAMA PADA PERUSAHAAN PERTAMINA (PERSERO) AKIBAT WANPRESTASI
}

\author{
I Wayan Eka Yasa, Nyoman Putu Budiartha, Desak Gde Dwi Arini \\ Fakultas Hukum, Universitas Warmadewa, Denpasar - Bali, Indonesia \\ wayanekayasa1997@gmail.com, budiarthaputu59@gmail.com, arinidesak1966@gmail.com
}

\begin{abstract}
Abstrak
Bentuk karakteristik perjanjian kerjasama pengusaha SPBU dengan PT. Pertamina (Persero) adalah menggunakan perjanjian baku atau standar. Adapun rumusan masalah adalah bagaiana bentuk karakteristik perjanjian kerjasama pada PT. Pertamina (Persero) dengan pengusaha SPBU, dan akibat hukum wanprestasi dalam perjanjian kerjasama pada PT. Pertamina (Persero). Metode Penelitian menggunakan penelitian hukum normatif, dengan pendekatan masalah menggunakan pendekatan perundang-undangan dan pendekatan konseptual. Konsep perjanjian baku ditinjau dari segi bentuknya, Dalam penelitian ini selalu ada kesepakatan tertulis, pertumbuhan yang kini sebagian besar kesepakatan dicapai dengan wujud yang dituliskan yang memakai kesepakatan yang terstandarisasi, dengan niat mengambil tindakan konkrit untuk menghemat waktu, uang dan tenaga. Jika pelaksanaan perjanjian kerja sama antara pengusaha SPBU dan PT dilanggar maka akan ada konsekuensi hukumnya. Pertarnina (Persero) melalui metode non-Iitigasi dan litigasi. Tidak membingungkan dikarenakan telah diundangkan dengan UU No. 30 Tahun 1999. tujuan daripada penelitian ini antara lain untuk mengetahui bentuk karakteristik perjanjian kerjasama pada PT. Pertamina (Persero) dengan pengusaha SPBU serta mengetahui akibat hukum wanprestasi dalam perjanjian kerjasama pada PT. Pertarnina (Persero).
\end{abstract}

Kata Kunci: Perjanjian Kerjasama, Perusahaan Pertamina, Wanprestasi.

\begin{abstract}
The characteristic form of the SPBU entrepreneur's cooperation agreement with PT. Pertamina (Persero) is using a standard or standard agreement. The formulation of the problem is how the characteristics of the cooperation agreement at PT. Pertamina (Persero) with SPBU entrepreneurs, and the legal consequences of default in the cooperation agreement at PT. Pertamina (Persero). The research method uses normative legal research, with a problem approach using a statutory approach and a conceptual approach. The concept of a standard agreement in terms of form, in this research there is always a written agreement, the growth of which is now mostly achieved in a written form that uses standardized agreements, with the intention of taking concrete actions to save time, money and energy.If the implementation of the cooperation agreement between the SPBU entrepreneur and PT is violated, there will be legal consequences. Pertarnina (Persero) through non-litigation and litigation methods. Not confusing because it has been promulgated by Law no. 30 of 1999. the purpose of this study, among others, to determine the form of the characteristics of the cooperation agreement at PT. Pertamina (Persero) with SPBU entrepreneurs as well as knowing the legal consequences of default in the cooperation agreement at PT. Pertarnina (Persero).
\end{abstract}

Keywords: CooperationAgreement, Compan Pertamina, Default.

\section{PENDAHULUAN}

Indonesia adalah kepulauan yang dianugerahi karunia Allah SWT dalam skala besar, berada diantara dua tanah raya dan juha dua lautan, memiliki banyak keunggulan kondisi alam dan kekayaan SDA. Migas rnerupakan salah satu diantara SDA mempunyai dampak besar pada kepentingan rakyat Indonesia. Minyak dan gas adalah salah saru sumber penting valuta asing merupakan usaha penataan Indonesia, bersarna-sarna mendukung serta menyempurnakan, dan merupakan unit proses guna mencapai keinginan penataan Indonesia, adalah untuk mencapai rakyat yang merata. Kemakmuran didistribusikan secara material dan spiritual berdasarkan Pancasila. Pertamina adalah perseroan Migas bumi yang dipunyai oleh Pemerintah Indonesia yang dibentuk pada 10 Desember 1957 yaitu bemama 
PT. Permina. Setelah UU No. 22 Tahun 200 I tentang Minyak dan Gas Bumi berlaku lalu terjadi perubahan nama menjadi PT. Pertamina (Persero). Kesepakatan kongsi yang membalut PT. Pertamina (Persero) yang ditandatangani oleh pebisnis SPBU adalah bentuk kesepakatan anyar yang sangat berbanding terbalik dengan kesepakatan pebisnis SPU yang lalu. Dalam kesepakatan kongsi ini, Penamina telah melaksanakan langkah pengawasan yang lebih sulit, baik iru dari langkah penataan, perbaikan, pendayagunaan dan pengurusan SPBU. Selain itu, Penamina telah menerapkan penyeragaman yaitu pada kualitas pelayanan yang harus dipenuhi oleh semua SPBU. Dalam masa perjanjian saat ini, para pengusaha SPBU harus memenuhi ketentuan PT Pertamina (Persero).

Perjanjian kerja sama disebut perjanjian standar dalam wujud anyar, itu ialah bentuk dari asas kebebasan malaksanakan kontrak yang telah diatur pada Pasal 1338 KUHPer, dan masih berkaitan erat dengan kewajiban melaksana kan persyaratan hukum perjanjian yang diatur pada Pasal 1320 KUHPerdata dimana kesepakatan ini adalah kesepakatan berdasarkan aturan dengan wujud yang bersifat karakteristik, disebut perjanjian standar, dimana harus dilaksanakan tinjauan yang kompeten mengenai hubungan antara Pertamina yaitu selaku penjual dan pebisnis SPBU selaku perantara. Hubungan hukum untuk menyelesaikan formulir. Ciri perjanjian ini adalah perjanjian standar (Mariam Darus Badrulzaman,1994;46) Berdasarkan penjelasan diatas maka dapat dirumuskan tujuan dari peneltian ini yakni untuk mengetahui karakteristik perjanjian kerjasama pada PT.Pertamina (Persero) dengan pengusaha SPBU dan mengetahui akibat hukum wanprestasi dalam perjanjian kerjasama pada PT. Pertamina (Persero).

\section{METODE PENELITIAN}

Penelitian yang penulis gunakan adalah penelitian hukum normatif (Sunaryati Hartono, 1994: 131141) yaitu penelitian dilakukan dengan menganalisis peraturan perundang-undangan yang berlaku. Mengenai sumber bahan hukum yang digunakan terbagi atas Bahan Hukum Primer adalah bahan hukum yang utama yang menjadi dasar kajian dari penulisan proposal skripsi ini. Bahan Hukum sekunder adalah adalah bahan hukum yang digunakan untuk menunjang atau membantu dalam memberikan pemahaman-pemahaman dan gambaran-gambaran serta teori-teori hukum yang digunakan untuk mengulas dan memecahkan persoalan-persoalan yang akan di teliti di dalam penelitian penulisan proposal skripsi. Bahan Hukum Tersier adalah bahan hukum yang memberikan pedoman dan interpretasi bagi bahan hukum tingkat pertama dan kedua. Untuk memperoleh bahan hukum primer, sekunder dan tersier, maka teknik inventarisasi atau penelusuran bahan hukum yang bersangkutan kemudian diklasifikasikan atau dikelompokkan dan didokumentasikan, dicatat, dikutip, diringkas, ditinjau sesuai kebutuhan dengan menggunakan pendekatan kualitatif. Setelah bahan hukum primer dan sekunder terkumpul, ini akan diolah dan dianalisis menggunakan metode penanganan bahan hukum yang sistematis.

\section{HASIL DAN PEMBAHASAN}

\section{Bentuk Karakteristik Perjanjian Kerjasama Pada Pt. Pertamina (Persero)}

Menurut akta pendirian, tujuan membangun Pertamina adalah menjalankan bisnis pada sektor industri Migas dan aktivitas bisnis terkait lainnya atau didukung oleh industri Migas di dalam maupun luar negeri.Menurut Pasal 2 ayat (2) PP No. 31 Tahun 2003, tujuan dari PT. Pertamina adalah:

a. Mencari laba atas prinsip-prinsip manajemen perusahaan yang ampuh dan berdaya.

b. Mendorong peningkatan aktivitas perekonomi guna meningkatkan ketentraman dan kenyamanan masyarakat.

Pertamina mengimplementasikan beberapa aktivitas bisnis guna meraih niat dan ambisi ini. Aktivitas bisnis meliputi:

a. Mengembangkan bisnis pada sektor migas serta produk olahannya dan turunannya.

b. Pada awal berdirinya telah menjalankan aktivitas bisnis pada sector panasbumi, tennasuk Pembangkit Listrik Tenaga Panas Bumi (PLTP) yang saat ini telah memasuki tahap akhir perundingan dan berhasil menjadi pembangkit listrik tenaga panas bumi Pertamina.

c. Mengembangkan dan manual LNG ataupun jenis lain diproduksi oleh pabrik LNG.

d. Melaksanakan aktivitas bisnis beda yang didukung dengan aktivitas bisnis yang dijelaskan pada angka 1,2 dan 3.

Sehubungan dengan aktivitas bisnis yang dijalankan Pertamina (adalah melakukan bisnis pada sektor migas serta produk olahannya dan turunannya), produk yang dihasilkan Pertamina antara 
lain produk olahan migas, termasuk bensin, Diesel, minyak tanah, solar, bahan bakar khusus, nonBBM, petrokirnia, pelumas dan gas yang terdiri dari LPG, BBG dan Musicool. Pertamina kemudian mendistribusikan dan memasarkan semua produknya, terutama untuk memenuhi kebutuhan masyarakat Indonesia. Dalam distribusi produk Pertamina (terutama BBM), Pertamina perlu didistribusikan ke semua penjuru negeri dengan kualitas baik dengan harga yang wajar (sesuai dengan peraturan yang berlaku) dalam wakru yang cukup dan tepat. Tingkat luas yang harus dicapai oleh Pertamina untuk distribusi bahan bakar minyak (BBM) membutuhkan Pertamina untuk bekerja dengan pihak ketiga, seperti mitra yang akan mendistribusikan BBM dan BBK, serta produk lain yang disediakan dan dijual oleh Pertamina. Pengusaha SPBU Sendiri adalah salah satu mitra Pertamina dalam kegiatan distribusi bahan bakar, dengan asumsi misi Pertamina untuk memenuhi kebutuhan pengguna mobil dengan cara yang mudah, cepat, tertib dan aman. Keberadaan pompa bensin sebagai agen distribusi bahan bakar rite) membuat orang lebih mudah unruk mendapatkan bahan bakar. Setelah berlakunya VU No. 22 tahun 2001, Aktivitas bisnis Migas dilimpahkan ke prosedur pasar, sehingga Pertamina bukan hanya lagi satu persero yang monopoli pada sektor bisnis Migas. Menghadapi kompetisi gratis, terutama di bidang rite) BBM, Pertamina pada masa ini berusaha guna marambah di semua sektor, termasuk fungsi outlet pompa gas ritel. Upaya yang dilakukan dalam transformasi ini adalah dengan memberikan standarisasi layanan pompa bensin Pertamina. Pertamina berjanji untuk memberikan layanan terbaik dengan istilah "Pertamina Way", dan pompa bensin yang berhasil menerapkan Pertamina Way memiliki hak untuk menerima sertifikasi "pasti pas".

\section{Akibat Hukum Wanprestasi dalam Perjanjian Kerjasama pada Pt. Pertamina (Persero) a. Penyelesaian Sengketa Diluar Pengadilan/ Non Litigasi}

Menurut Amriani (2012:12), sengketa adalah suatu situasi dimana ada pihak yang merasa dirugikan oleh pihak lain, yang kemudian pihak tersebut menyampaikan ketidakpuasan ini kepada pihak kedua. Jika situasi menunjukkan perbedaan pendapat, maka terjadi lah apa yang dinamakan dengan sengketa. Fenomena perselisihan dan atau pertengkaran yang terjadi ditengah-tengah masyarakat menjadi fakta yang tidak terbantahkan lagi. Sengketa ini dapat terjadi diawali karena adanya perasaan tidak puas di mana ada pihak yang merasa dirugikan dan kemudian perasaan tidak puas ini menjadi conflict of interest yang tidak terselesaikan sehingga menimbulkan suatu konflik (Suyud Margono, 2000: 34).

(Abdulkadir Muhammad, 1990; 17) Bahwa penyelesaian terjadinya wanprestasi antara pengusaha SPBU dengan PT. Pertamina (Persero) menggunakan cara mengatasi perselisihan dengan non litigasi, melalui beberapa cara mengatasi perselisihan:

1. Negosiasi

Negoiasi adalah proses merundingkan atau mencapai kesepakatan tentang masalah tertentu antara kedua pihak. Negosiasi sederhana adalah negosiasi yang hanya dilakukan oleh pihak-pihak terkait. Pada saat yang sama, negosiasi yang kompleks akan melibatkan negosiator khusus, seperti pengacara sebagai negosiator, dan setiap orang memiliki negosiatomya sendiri. Sementara itu ,Fisher dan Ury menyebutkan dua teknik negosiasi yaitu teknik yang bertumpu pada posisi (positional based negotiation) dan teknik yang bertumpu pada kepentingan (interest based negotiation) 6 Seorang perunding pada negosiasi yang bertumpu pada posisi akan mempertahankan apa yang diinginkannya tanpa menunjukkan keinginan untuk bekerjasama dengan pihak lain. Berbeda dengan perunding yang menggunakan teknik yang bertumpu pada posisi, perunding dengan teknik yang bertumpu pada kepentingan dalam meminta dan memberikan konsesi akan berusaha memahami kepentingan pihak lain di samping kepentingannya sendiri.

2. Penyelesaian Melalui Mediasi

Mediasi adalah upaya untuk menyelesaikan perselisihan, perselisihan minat, sengketa PHK dan perselisihan antara serikat pekerja I serikat pekerja di sebuah perusahaan. Pemerintah dapat menunjuk mediator yang bertanggung jawab atas mediasi atau mediator yang dapat menyelesaikan default perselisihan. Pengangkatan dan mediator ditentukan oleh Menteri Tenaga Kerja. Jika kesepakatan unruk menyelesaikan perselisihan telah dicapai melalui mediator, para pihak dan mediator menandatangani "kesepakatan bersama" dan kemudian mendaftarkan kesepakatan tersebut di pengadilan hubungan kerja di pengadilan negeri setempat. Jika tidak ada kesepakatan antara pihak-pihak yang disengketakan, mediasi dapat dilakukan. Mediasi dapat dikatakan sebagai upaya para pihak yang dapat dilakukan para pihak sebelum menjangkau pengadilan. Dalam fase 
mediasi dari kecepatan solusi masalah sangat cepat, tidak lebih dari 30 hari kerja, mediator harus memulai pertemuan mediasi dalam waktu 7 hari setelah ditunjuk.

3. Penyelesaian Melalui Konsiliasi

Konsiliasi merupakan suatu metode di dalam penyelesaian suatu sengketa yakni dengan menyerahkannya kepada sebuah konsiliator untuk kemudian menjelaskan serta juga menguraikan segala jenis fakta serta juga setelah itu akan membuat suatu usulan suatu keputusan penyelesaian, Tetapi usulan keputuan tersebut memiliki sifat tidak mengikat (Huala Adolf: 2005). Penyelesaian melal ui konsiliator adalah pejabat mendama-dusun yang ditunjuk dan diberhentikan oleh Menteri Tenaga Kerja. Tugas paling penting dari konsiliator adalah untuk memanggil saksi atau pihak terkait dalam waktu tujuh hari setelah menerima penyelesaian konsiliator. Setelah perjanjian tercapai, petugas konsiliator dapat memanggil para pihak yang diperdebatkan dan mencapai kesepakatan bersama.

4. Penyelesaian Melalui Arbitrase

Suatu tindakan hukum di mana ada pihak yang menyerahkan sengketa atau selisih pendapat antara dua orang atau lebih maupun dua kelompok atau lebih kepada seseorang atau beberapa ahli yang disepakati (Abdurrasyid, 2002: 16). VU No. 30 Tahun 1999 tentang Arbitrase dan Altematif Penyelesaian Sengketa mengatur tentang penyelesaian sengketa secara umum melalui arbitrase, dan undang-undang ini berlaku untuk bidang sengketa perdagangan. Undang-undang boleh menyelesaikan pertikaian iru melalui timbang tara untuk menyelesaikan pertikaian kepentingan semua pihak. Ditentukan sebagai arbiter sesuai dengan Pasal 31 (I). Pertikaian itu boleh memilih arbitrator pilihannya. Keputusan arbiter yang mengajukan kecurigaan dapat diajukan ke pengadilan negeri unruk ditolak dengan mencantumkan alasan yang dapat dibenarkan atas kecurigaan tersebut. Putusan pengadilan negeri dapat membuat kepurusan tentang alasan penolakan dan di mana tidak ada pembelaan lebih lanjut yang dapat diajukan. Jika perdamaian tercapai, arbiter harus menandatangani perjanjian damai oleh kedua belah pihak di hadapan arbiter atau komite arbitrase.

Perbuatan mediasi telah terdaftar di pengadilan, dan juga dapat ditegakkan oleh pengadilan atau vonis seperti biasa. Putusan perjanjian arbiter dibuat dan tiga kali rangkap tiga untuk setiap pihak, karena vonis secara legal secara legal dan tidak dapat diajukan lagi, atau perselisihan yang sama tidak dapat diajukan lagi. Penyelesaian perselisihan akibat pelanggaran kontrak dalam perjanjian kerja sama ini melalui arbitrase didasarkan pada Perjanjian antara kedua pihak didasarkan pada perjanjian kerja bersama, dan jika perjanjian kerja bersama tidak memberikan solusi arbitrase, kedua pihak dapat mencapai kesepakatan awal termasuk penyelesaian sengketa melalui arbitrase.

Berdasarkan kesepakatan para pihak untuk menyelesaikan sengketa gaga! bayar dalam perjanjian kerja sama ini melalui arbitrase, karena putusan arbitrase bersifat final dan permanen tidak dapat diajukan ke pengadilan kecuali dapat dicabut ke Mahkamah Agung Republik Indonesia dalam keadaan tertentu.

\section{b. Penyelesaian Sengketa di dalam Pengadilan/Litigasi}

Pengertian peradilan menurut Kamus Umum Bahasa Indonesia merupakan segaJa sesuatu mengenai perkara pengadilan. (Poerwadarrninta, W .J .S ., 1984: 16-17) Penyelesaian sengketa secara litigasi mengandung pengertian sengketa tersebut diselesaikan melaJui lembaga peradilan. SebaJiknya penyelesaian sengketa secara non litigasi mengandung pengertian bahwa sengketa tersebut diselesaikan di luar Iembaga peradilan. Bentuk penyelesaian non litigasi ditentukan sepenuhnya oleh masyarakat, termasuk di kalangan masyarakat bisnis.(Hendry Campbell Black, 1991:70.)

Baik di negara maju maupun berkembang, ha! ini sudah menjadi masalah umum di negara manapun.Ketika menyelesaikan perselisihan antara masyarakat dan mereka yang mencari keadilan, departemen kehakiman banyak menuai kritik, apalagi daJam bidang perdagangan dan bisnis sangat banyak dan beragama. Secara umum, mereka mengkritik sistem peradilan karena prosesnya yang lambat, mahal dan rumit. Kritikus menilai mahalnya biaya litigasi tidak hanya berdampak pada negara maju tetapi juga kehidupan ekonomi negara berkembang termasuk lndonesia (Suyud Margono,2000:34.)

Sebenarnya masih banyak kritik yang bisa dilukiskan, namun dari uraian di atas terlihat bahwa meskipun berstatus dan keberadaan sistem peradilan sebagai "katup penekan dan pilihan terakhir" (yaitu katup penekan dan jalan), terdapat masalah dalam sistem peradilan. Betapa rumitnya. Mencari solusi akhir untuk kebenaran dan keadilan, yang dapat mengurangi kepercayaan publik pada 
keadilan.Sifat formaJ dan teknis peradilan biasanya mengarah pada penyelesaian sengketa yang berlarut-larut, yang membutuhkan waktu lama. Selain itu, daJam sengketa komersiaJ, diperlukan penyelesaian sengketa yang cepat, murah, dan informal.

\section{IV .SIMPULAN DAN SARAN}

\section{Simpulan}

Berdasarkan dari hasil analisis dapat disimpulkan bahwa:

a. Bentuk karakteristik perjanjian kerjasama pengusaha SPBU dengan PT. Pertamina (Persero) mempergunakan kesepakatan standar. Dalam penelitian ini, konsep kesepakatan formal selalu merupakan kesepakatan tertulis. Dalam perkembangannya saat ini, sebagian besar perjanjian kerja sama diformulasikan dalam bentuk tertulis menggunakan perjanjian standar, dengan tujuan mengambil tindakan konkret untuk menghemat waktu, uang, dan energi.

b. Jika pelaksanaan perjanjian kerja sama antara pengusaha SPBU dan PT dilanggar maka akan ada konsekuensi hukumnya. Pertamina (Persero) melalui metode non-litigasi dan litigasi. Dari kedua opsi tersebut, pihak yang bersengketa paling banyak tertarik pada non litigasi (metode arbitrase). Alasannya, masyarakat yakin bahwa proses penyelesaian non litigasi (arbitrase) dapat berjalan cepat dan berbiaya rendah, serta tidak mernbutuhkan waktu lama. Waktu dan birokrasi. Tidak membingungkan karena sudah jelas diatur dalam UU No. 30 Tahun 1999.

\section{Saran}

Berdasarkan simpulan tersebut diatas, dapat dikemukakan saran kepada para pihak terkait, sebagai berikut:

a. Kepada Perusahaan karena perjanjian kerjasama antara pengusaha SPBU dengan PT. Pertamina (Persero) merupakan bentuk perjanjian baku atau standar seyogyanya para pihak sebelum menandatangani perjanjian kerjasama tersebut agar terlebih dahulu membaca dan memahami isi perjanjian tersebut secara jelas.

b. Kepada masyarakat Untuk menghindari terjadinya sengketa wanprestasi para pihak yang sudah sepakat membuat perjanjian kerjasama wajib taat, paruh dan melaksanakan isi perjanjian kerjasama yang telah dibuat sebagai pencerminan dari salah satu asas itikad baik.

\section{DAFTAR PUSTAKA}

Abdurrasyid Priyatna. 2002. Arbitrase dan Arbitrase dan Alternatif Penyelesaian Sengketa. Jakarta: Fikahati Aneska

Adolf, Haula. (2005). Hukum Ekonomi Internasional Suatu Pengantar. PT. Raja Grafindo Persada: Jakarta.

Amriani, Nurnaningsih, (2012), MEDIASI: Aternatif Penyelesaian Sengketa di Pengadilan, PT.Raja Grafindo Persada. Jakarta.

Fisher, R. and W. U. (1991). Negotiating an Agreement without Giving In. Bussiness Book. London.

Hendry Campbell Black, (1991), slaw Dictionary: Definitionof the Termsand Harases of American and EnglishJuris Prudence, Ancient and Modern. ST. Paul: West Publishing Co.

Mariam Dams Badrulzaman, 1994, Aneka Hukum Bisnis, alumni, Bandung, Kompilasi Hukum Perikatan, Citra Aditya Bhakti.

Muhammad, A. (1990). Hukum Perikatan (Cetakan 2).PT.Citra Aditya Bakti. Bandung.

Purwadininggrat W.J.S.(1994). Kamus Umum Bahasa Indonesia.

Sunaryati Hartono, (1994), Penelitian Hukum di Indonesiapada Akhir Abad ke-20, Alumni, Bandung.

Suyud Margono, (2000), ADR \& Arbitrase Proses Pelembagaan dan Aspek Hukum, Ghalia Lndonesia, Bogor. 